\title{
EVALUATION FOR EARTHQUAKE-RESISTANT CAPABILITY OF UN-LANDING STEEL ARCH
}

\author{
Qinghua $\operatorname{Han}^{1,2}$, Yan $\mathrm{Lu}^{1,2^{*}}$ and Qiuhong Zhao ${ }^{1,2}$ \\ ${ }^{I}$ School of Civil Engineering, Tianjin University, Tianjin 300072, China; \\ ${ }^{2}$ Key Laboratory of Coast Structure Safety (Tianjin University), Ministry of Education, Tianjin 300072, China \\ *(Corresponding author: E-mail: yanlu86@tju.edu.cn)
}

Received: 31 October 2013; Revised: 5 September 2014; Accepted: 29 September 2014

\begin{abstract}
This paper presents research results on the earthquake-resistant capability of the un-landing steel arch. A shaking table test of an un-landing solid-web steel arch was carried out to present the seismic behavior. During the shaking table test, the acceleration response at the arch-top is largest. The maximum displacement response and the maximum stress at the quarter point of the arch is larger than other test points. The added braces could effectively help decreasing the displacement and deformation of the un-landing steel arch. The seismic response under the Tianjin wave is the largest while that under the Loma Prieta wave is the least, since the predominant frequency of the Tianjin wave is closest to the fundamental frequency of the model. Then IDA approach is applied in the un-landing steel arch. A single IDA curve is plotted, which fits the test result. By the IM-based rule, the capacity point of the structure is acquired. Finally, the earthquake-resistant capability of the un-landing latticed steel tubular arch is evaluated by the multi-record IDA study from a real project. A suite of records by having mean, $16 \%, 84 \%$ fractiles is summarized.
\end{abstract}

Keywords: Un-landing steel arch, earthquake-resistant capability, shaking table test, IDA approach, capacity point

\section{INTRODUCTION}

Earthquake may cause serious damage and even collapse of the spatial structures, and it is necessary to study the earthquake-resistant capability of spatial structures such as steel arch. In order to meet the requirement of the use space, many steel arches are the un-landing steel arches. The ends of the steel arch are supported on the steel column or other structures. An un-landing solid-web steel arch was adopted in the Xianglujiao light-rail station in Dalian, which had a span of $23.2 \mathrm{~m}$ and a rise-to-span ratio varying from 0.08 to 0.12 (Figure 1(a)). The ends of I-type steel arch were supported on the I-type steel column. An un-landing latticed steel tubular arch was adopted in the Beidaihe railway station canopy with a span of $68.6 \mathrm{~m}$ (Figure1(b)). The ends of latticed steel tubular arch were supported on the latticed steel column.

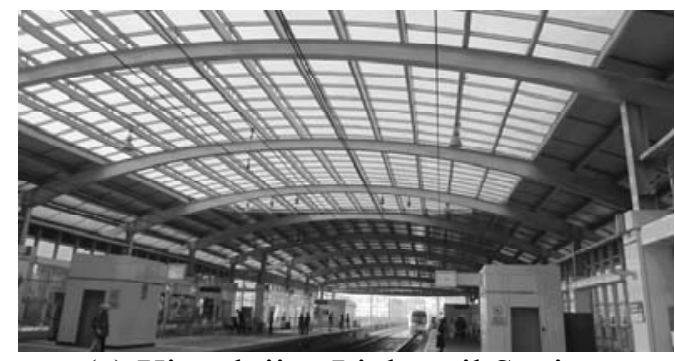

(a) Xianglujiao Light-rail Station

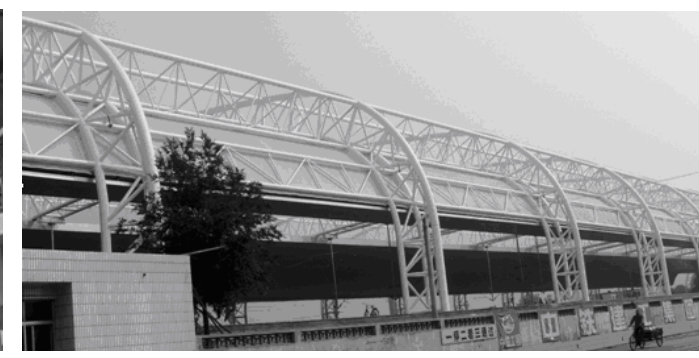

(b) Beidaihe Railway Station Canopy

Figure 1. Project Photos

A shaking table test is a direct way to study the earthquake response of structures, and shaking table tests were conducted on various spatial structures before. The model-frequency behavior, earthquake response, failure mechanism, failure mode and energy dissipation mechanism were investigated[1-6]. All of this will help to provide the test support for the research theory about structural seismic performance. 
Incremental dynamic analysis (IDA) approach, proposed by Vamvatsikos and Cornell[7], is a computational-based methodology. The IDA approach involves performing nonlinear dynamic analysis of a prototype structural system under a suit of ground motion records, each scaled to several IM(intensity measures) levels designed to force the structure all the way from elastic response to final global dynamic instability(collapse)[8-11]. This paper presents the earthquake-resistant capability of un-landing steel arch by the shaking table test and IDA approach.

\section{FUNDAMENTALS OF SINGLE-RECORD IDA}

Incremental Dynamic Analysis (IDA) is a parametric analysis method that has recently emerged in several different forms to estimate more thoroughly structural performance under seismic loads. There are several fundamentals of single-record IDA.

1) A monotonic scaled ground motion intensity measure (or simply intensity measure, IM). Common examples of scalable IMs are the peak ground acceleration (PGA), peak ground velocity, the $\xi=5 \%$ damped spectral acceleration at the structure's first-mode period $\left(S_{\mathrm{a}}\left(T_{1} ; 5 \%\right)\right)[12]$. IM is PGA in this paper.

2) Damage measure (DM) or structural state variable is a non-negative scalar DM that characterizes the additional response of the structural model due to a prescribed seismic loading. Possible choices could be maximum base shear, node rotations, peak storey ductilities, various proposed damage indices (e.g. a global cumulative hysteretic energy, a global Park-Ang index or the stability index proposed by Mehanny), peak roof drift)[12]. In the spatial structure, the maximum displacement can describe the structure response[13]. Therefore, DM is the maximum displacement in this paper.

3) The scale factor (SF) of a scaled accelerogram. The SF constitutes a one-to-one mapping from the original accelerogram to all its scaled images.

A single-record IDA study is a dynamic analysis study of a given structural model parameterized by the scale factor of the given ground motion time history.

\section{EXPERIMENTAL SET-UP AND PROCEDURE}

\subsection{Model Design and Sensor Placement}

The test model was a un-landing solid-web steel arch made of stainless steel, as shown in Figure 2. From the coupon tests, elastic modulus $E$ of the stainless steel is $2.01 \times 10^{5} \mathrm{~N} / \mathrm{mm}^{2}$, the yield strength $f_{\mathrm{y}}$ is $212 \mathrm{~N} / \mathrm{mm}^{2}$, and the ultimate strength $f_{\mathrm{u}}$ is $620 \mathrm{~N} / \mathrm{mm}^{2}$.

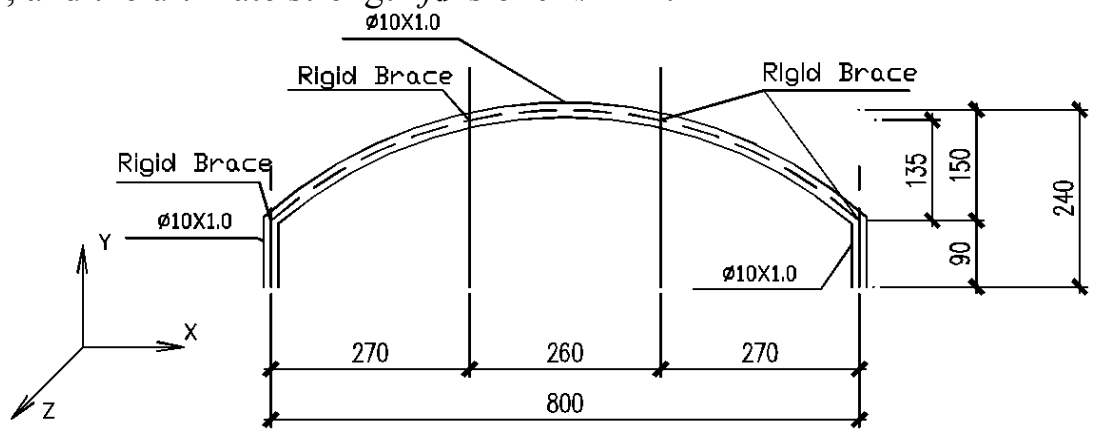

Figure 2. Configuration of the Un-landing Steel Arch (Unit: mm) 
Studies have been conducted on the stability and buckling of steel arches, and design rules have been proposed for both the in-plane buckling [14-15] and the out-of-plane buckling[16-17]. Steel arches with sufficient lateral bracing would fail due to the plastic collapse instead of the in-plane or out-of-plane buckling[18]. Therefore, 4 braces were applied along the arch with equal distance in order to avoid the out-of-plane buckling, and both columns were fixed at the bottom[19].The braces were welded to the test model on one end, and sliding against a bracing frame on the other end(Figure 3). According to the Chinese code[20], an additional mass of $25.8 \mathrm{~kg}$ was attached to the test model, which represented the dead load and half of the live load applied on the arch-frame structure. Each mass block was $2.87 \mathrm{~kg}$. Accelerometers, displacement sensors and strain gauges were used to monitor the response of the test model, and the location of the 4 displacement sensors (named U1, U2, U3, U4), 4 accelerometers (named A1, A2, A3, A4) and 7 strain gauges (named S1, S2, S3, S4, S5, S6, S7) are shown in Figure 4 below. Due to symmetry, most of the strain gauges were installed on the right half of the test model, while there were only 2 gauges installed on the left half as checkpoints.

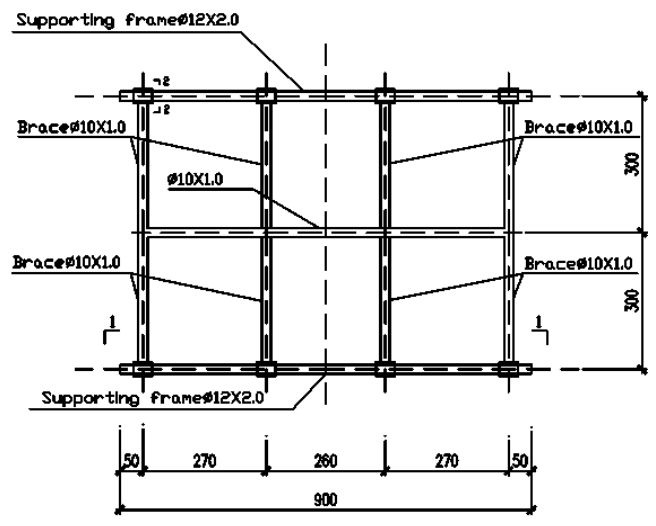

(a) Test Model Layout

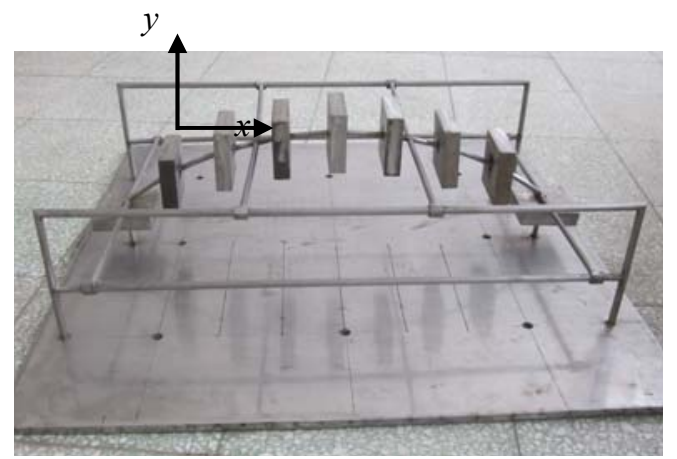

(b) A Photograph of the Test Model

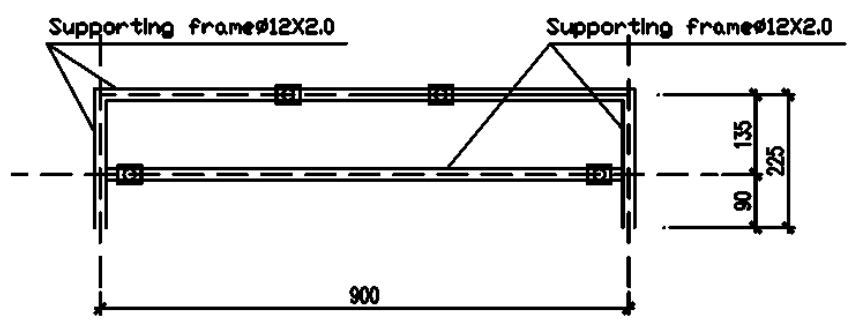

(c)1-1Cutaway Drawing

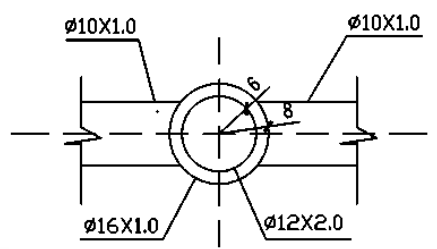

(d)2-2 Cutaway Drawing

Figure 3. Brace and Supporting Frame Layout

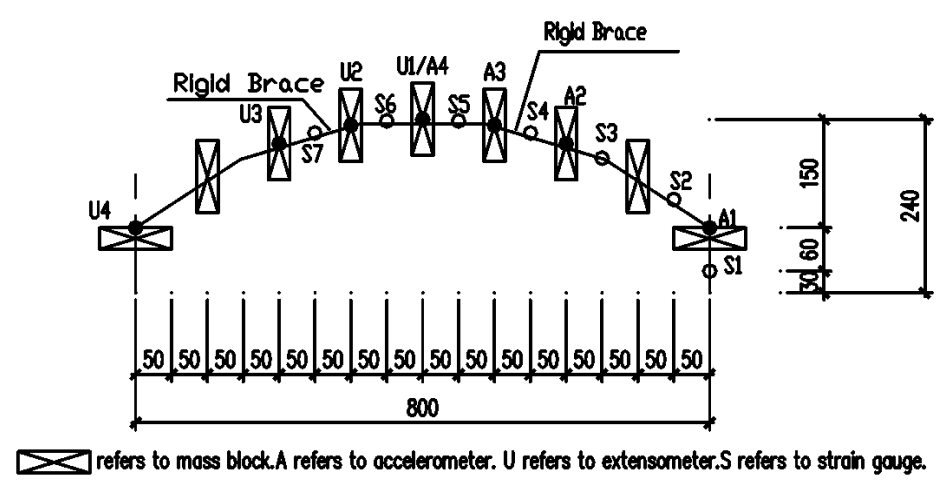

Figure 4. Sensor Placement 


\subsection{Ground Motion Record and Loading Plan}

According to the shaking table test method about steel structure[21-23], three earthquake records were selected as input for the shaking table test, in order to evaluate the seismic performance of the test model under different levels of the seismic excitations, including the Tianjin earthquake (1976, NS), the Taft earthquake (1952, NS), and the Loma Prieta earthquake (1989, NS). White noise of 30 s was applied before each test. The ground motion record was compacted 10 times according to the natural frequency of the test model. After the Fourier transform, the main frequency is $10-12 \mathrm{~Hz}$ for the Tianjin wave, $12-18 \mathrm{~Hz}$ for the Taft wave, and $15-18 \mathrm{~Hz}$ for the Loma Prieta wave. The loading plan is shown in Table 1.

Table 1. Loading Plan of the Shaking Table Test

\begin{tabular}{|c|c|c|c|}
\hline Process & Case \# & Input Record & PGA (g) \\
\hline \multirow{7}{*}{ Process 1} & 1 & White noise & 0.1 \\
\hline & 2 & Tianjin wave & 0.07 \\
\hline & 3 & Taft wave & 0.07 \\
\hline & 4 & Loma Prieta wave & 0.07 \\
\hline & 5 & Tianjin wave & 0.14 \\
\hline & 6 & Taft wave & 0.14 \\
\hline & 7 & Loma Prieta wave & 0.14 \\
\hline \multirow{4}{*}{ Process 2} & 8 & White noise & 0.1 \\
\hline & 9 & Tianjin wave & 0.22 \\
\hline & 10 & Taft wave & 0.22 \\
\hline & 11 & Loma Prieta wave & 0.22 \\
\hline \multirow{4}{*}{ Process 3} & 12 & White noise & 0.1 \\
\hline & 13 & Tianjin wave & 0.40 \\
\hline & 14 & Taft wave & 0.40 \\
\hline & 15 & Loma Prieta wave & 0.40 \\
\hline \multirow{4}{*}{ Process 4} & 16 & White noise & 0.1 \\
\hline & 17 & Tianjin wave & 0.62 \\
\hline & 18 & Taft wave & 0.62 \\
\hline & 19 & Loma Prieta wave & 0.62 \\
\hline \multirow{5}{*}{ Process 5} & 20 & White noise & 0.1 \\
\hline & 21 & Tianjin wave & 0.8 \\
\hline & 22 & Tianjin wave & 1.0 \\
\hline & 23 & Tianjin wave & 1.2 \\
\hline & 24 & Tianjin wave & 1.5 \\
\hline
\end{tabular}

\subsection{System Response}

\subsubsection{Self-vibration Characteristic}

Firstly, the model was scanned by the white noise before the ground motion was input. The three natural frequencies were tested. The first-order frequency of the test model was $12.25 \mathrm{~Hz}$, which is close to the main frequency of Tianjin wave. And the damping ratio was about 0.012 . From Figure 5 , the natural frequency shows a decrease trend and fall by $1 \%-7 \%$. The results show than internal damage grows for the model after the earthquake. 


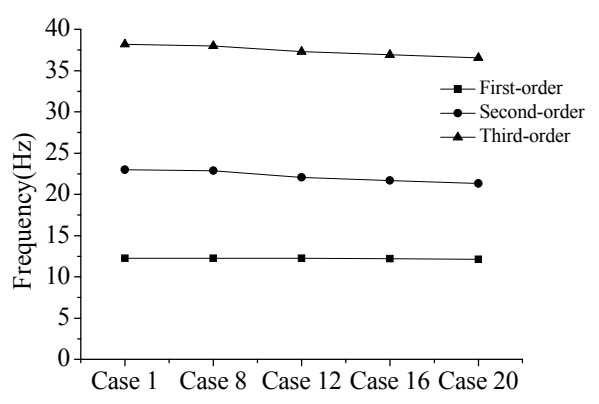

Figure 5. The Influence of Different Seismic Wave on the Natural Frequencies

\subsubsection{Acceleration Response}

As the acceleration amplitude of the ground motion input increases, the acceleration amplification factor $\beta$ ( $\beta=$ the peak acceleration of a test point/peak acceleration of the test table) increases at first and then decreases. This phenomenon reflects that there is internal damage in the model after the earthquake, which makes the structural stiffness decline (Figure 6). It is clear that the acceleration response at the arch-top (A4) is largest.

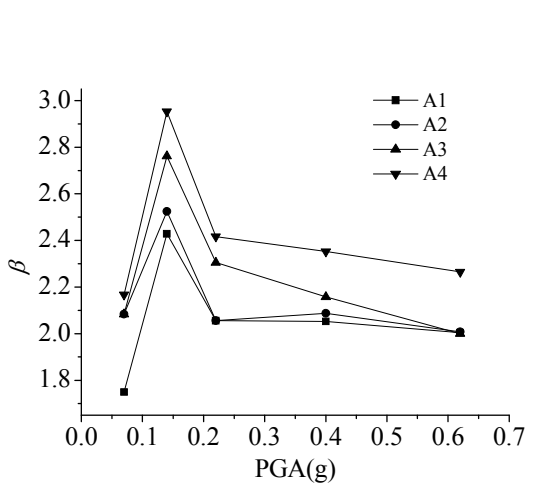

(a) Tianjin Wave

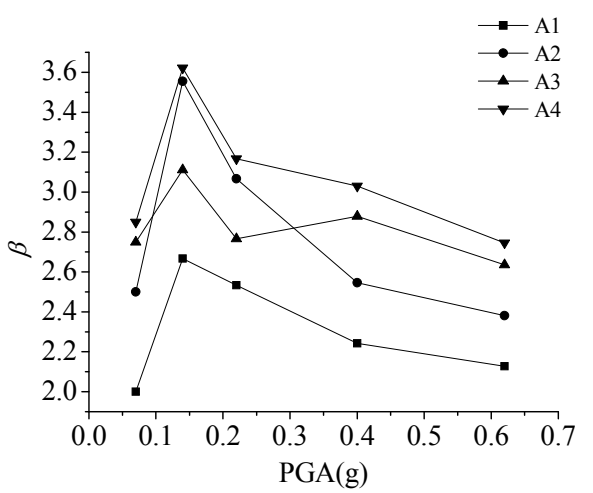

(b)Taft Wave

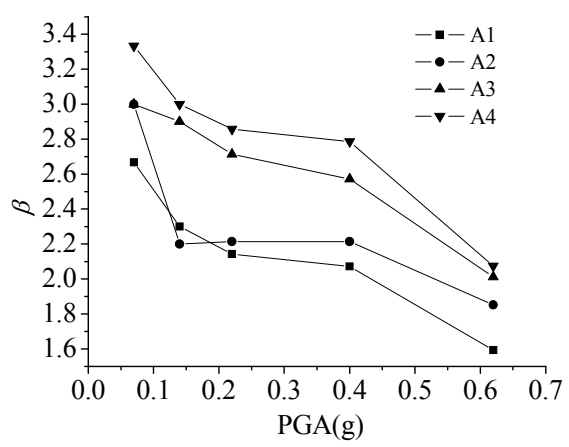

(c)Loma Prieta Wave

Figure 6. Influence of Different PGA on $\beta$ 


\subsubsection{Displacement Response and Stress Results}

The maximum displacement response $U_{\max }$ at the quarter point of the arch is larger than other test points, as shown in Figure 7. Figure 8 shows that the maximum stress $\sigma_{\max }$ at the quarter point of the $\operatorname{arch}(\mathrm{S} 4, \mathrm{~S} 7)$ is larger than the $\sigma_{\max }$ at the arch-top and at the arch-column connection. All these results reflect that the added braces could effectively help decreasing the displacement and deformation of the arch-frame. When PGA $\leq 0.62 \mathrm{~g}$, the maximum stress $\sigma_{\max }$ under the Tianjin wave is the largest while $\sigma_{\max }$ under the Loma Prieta wave is the least, since the predominant frequency of the Tianjin wave is closest to the fundamental frequency of the model.

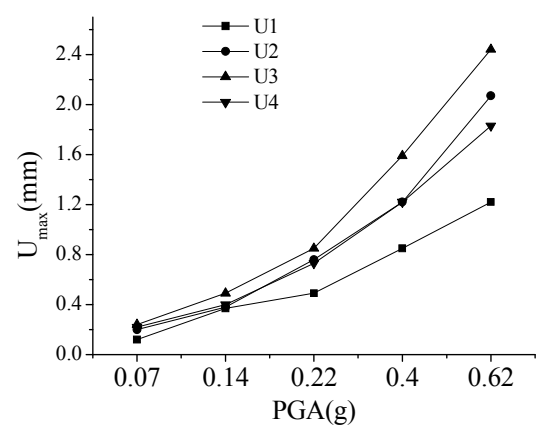

(a) Tianjin Wave

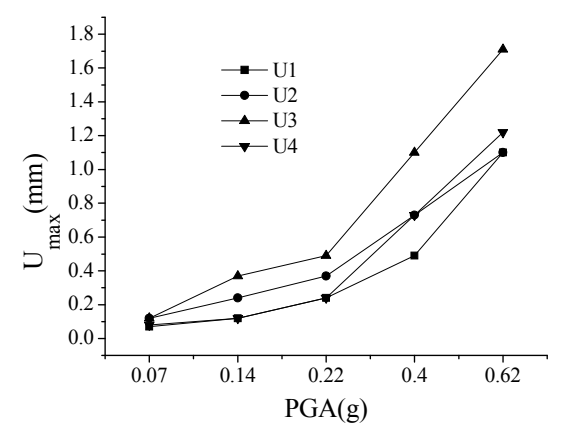

(b)Taft Wave

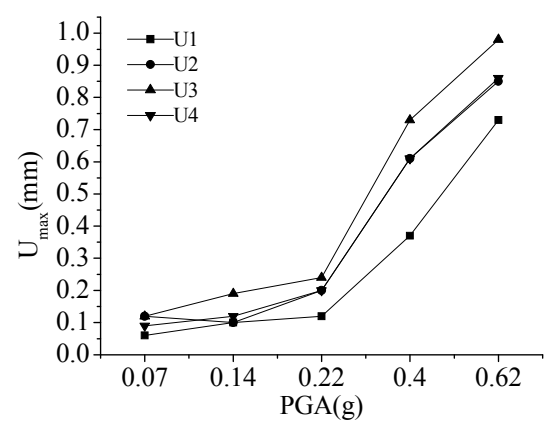

(c)Loma Wave

Figure 7. Displacement Response of the Test Points

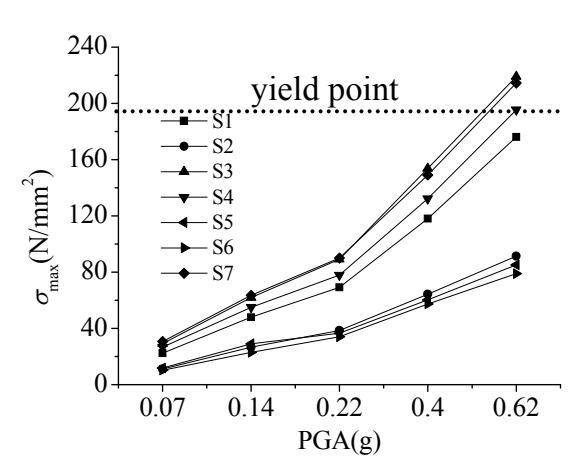

(a) Tianjin Wave

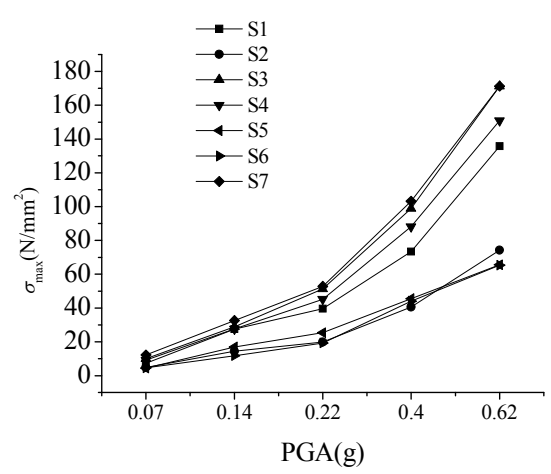

(b)Taft Wave 


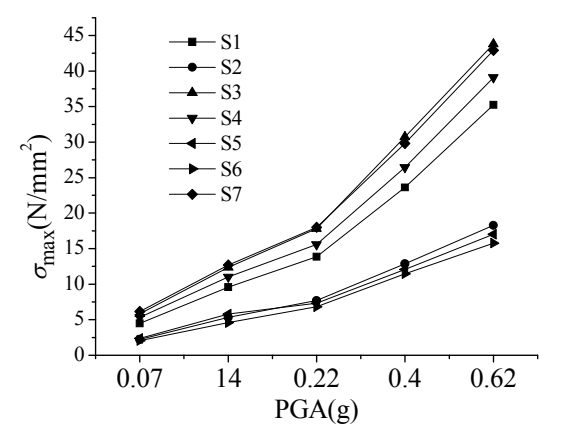

(c)Loma Prieta Wave

Figure 8. Maximum Stress of Different Test Points

\subsubsection{Test Analyses}

After Process 4 of the shaking table test, PGA of the Tianjin wave continued to increase in order to study the development of plastic deformation and the failure mechanism of the arch-frame. When PGA of the ground motion records was smaller than $0.40 \mathrm{~g}$, the behavior of the model was mainly elastic. When PGA of the ground motion records was $0.62 \mathrm{~g}$, the maximum stress in the model was $214.5 \mathrm{~N} / \mathrm{mm}^{2}$ and larger than $f_{\mathrm{y}}($ Figure $8(\mathrm{a}))$. then plastic zone started to form in the test model. When PGA of the ground motion record was $0.80 \mathrm{~g}$, the plastic zone started to spread. Finally, when PGA $=1.2 \mathrm{~g}$, the arch top deformed along the X direction(Figure 9(a)). The test model was in-plane antisymmetric deformation(Figure 9(b)). The braces reduced the lateral deformation of the model. The test model lost the bearing capacity.

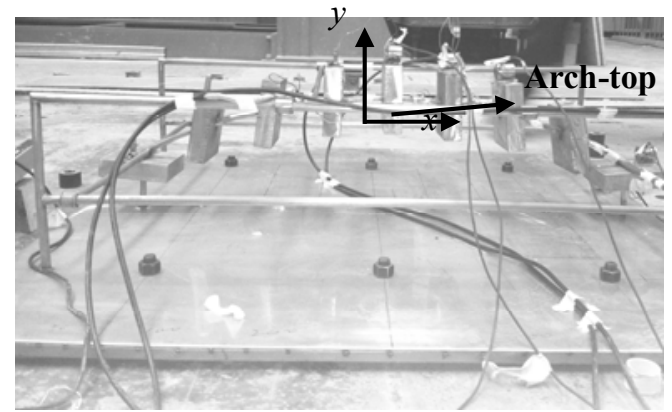

(a) Front View

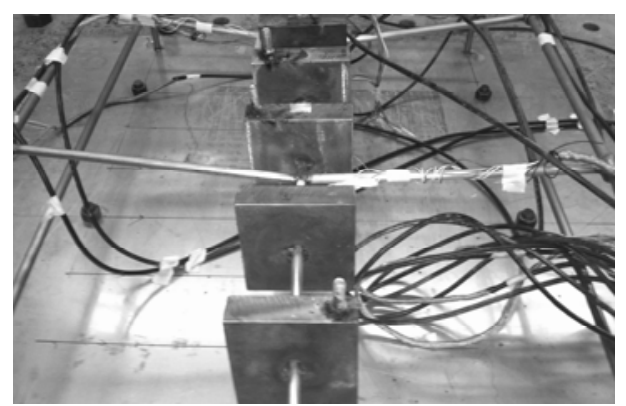

(b)Side View

Figure 9. Failure Mode of the Test Model

\subsection{Incremental Dynamic Analysis}

Performance levels or limit-states are important ingredients of PBEE (Performance-Based Earthquake Engineering), and the IDA curve contains the necessary information to assess them. The material model was elastic perfectly-plastic with the elastic modulus and yield strength acquired from the coupon tests. The model was constructed with beam element Beam188, and the additional mass was modeled with mass element Mass21. The material nonlinear effects as well as geometrically nonlinear effects have been considered to simulate the realistic behavior of the arch as accurately as possible. By restraining the nodes displacement of $\mathrm{Z}$ direction may simulate the lateral braces. The structural model is shown in Figure 10. The first-order frequency is $13.7 \mathrm{~Hz}$ by ANSYS, which is close to the value by the shaking table test $(12.25 \mathrm{~Hz})$. 


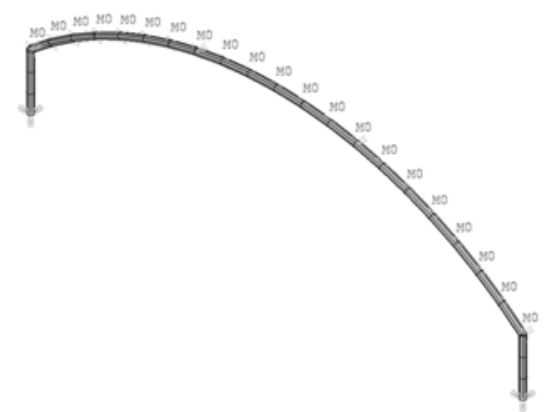

Figure 10. Numerical Analysis Model

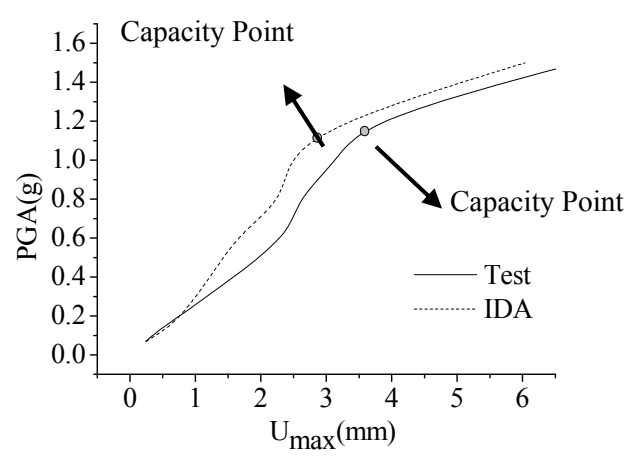

Figure 11. Maximum Displacement vs. PGA Curve

When a statement or a rule is satisfied, the structure reaches a limit-state. There are DM-based rule and IM-based rule. First comes the DM-based rule, which is generated from a statement of the format: "If $\mathrm{DM} \geq \mathrm{CDM}$ then the limit-state is exceeded". DM is a damage indicator. Different spatial structures have different structure response. Hence, it is difficult to rule the $\mathrm{C}_{\mathrm{DM}}$. The IM-based rule

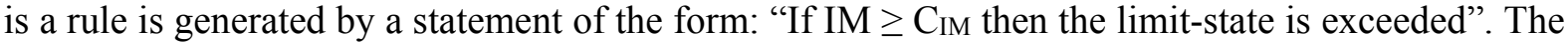
IM-based rule can refer to the $20 \%$ tangent slope approach ruled by FEMA[24]. In effect it is that the last point on the curve with a tangent slope equal to $20 \%$ of the elastic slope is defined to be the capacity point. Taking the maximum displacement of U3 for example (Figure 11), the IDA results are slightly smaller than the test results. According to the IM-based rule, when the structure comes to the capacity point, PGA is $1.20 \mathrm{~g}$ by both the test and IDA approach. It is also shown that the IDA curves can assess the earthquake-resistant capability of the spatial structures.

\section{EVALUATION OF EARTHQUAKE-RESISTANT CAPABILITY OF THE UN-LANDING LATTICED STEEL TUBULAR ARCH}

\subsection{Project Introduction}

The earthquake-resistant capability of an un-landing latticed steel tubular arch was evaluated using the IDA approach from a real project described in Figure 1(b). The project is a railway platform canopy, which consists of thirteen $68.6 \mathrm{~m}$-span transverse latticed steel tubular arch and three longitudinal steel-tube trusses, as shown in Figure 12. The space between each arch is $22 \mathrm{~m}$ and the overall canopy length is $270 \mathrm{~m}$. The height of the truss column is $6.8 \mathrm{~m}$. One un-landing latticed steel tubular arch was analyzed by ANSYS. The truss type is triangular truss as shown in Figure 13, and the member section is steel tube shown in Table 2. Material of the steel tubes is Q235B. The chords were simulated by Beam188. The web members were simulated by Link8. By restraining the nodes displacement of $\mathrm{Z}$ direction may simulate the longitudinal steel-tube trusses.

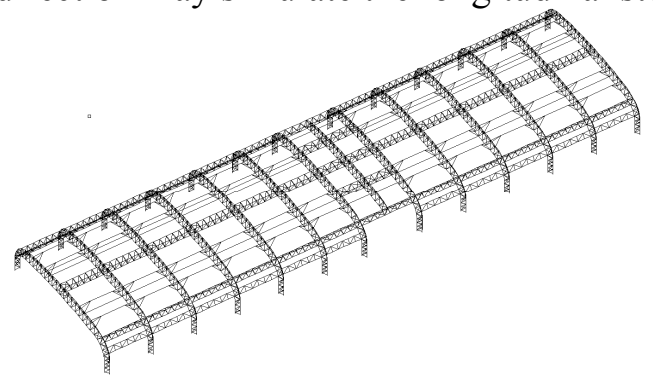

Figure 12. A Railway Platform Canopy 


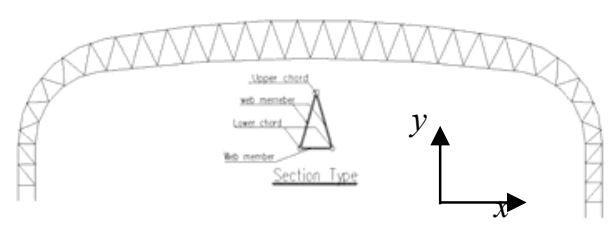

Figure 13. Configuration of An Un-landing Latticed Steel Tubular Arch

Table 2. Section Type of the Un-landing Latticed Steel Tubular Arch

\begin{tabular}{|c|c|}
\hline Member & Section Type \\
\hline Upper chord of the truss-arch & $\Phi 550 \times 14$ \\
\hline Lower chord of the truss-arch & $\Phi 426 \times 14$ \\
\hline Web member of the truss-arch & $\Phi 114 \times 6, \Phi 168 \times 8$ and $\Phi 273 \times 8$ \\
\hline Upper chord of the truss-column & $\Phi 550 \times 18$ \\
\hline Lower chord of the truss-column & $\Phi 426 \times 18$ \\
\hline Web member of the truss-column & $\Phi 114 \times 6, \Phi 168 \times 8$ and $\Phi 273 \times 8$. \\
\hline
\end{tabular}

\subsection{Selection of the Ground Motion Record}

15 ground motion records for duration of 20s were selected as the input ground motion in Table 3 from PEER Strong Motion Database. The PGA has been increased 8 10 times and the step is $0.3 \sim 0.5 g$.

Table 3. The Suite of 15 Ground Motion Records

\begin{tabular}{|c|c|c|c|}
\hline No. & Event & $\begin{array}{c}\text { Moment } \\
\text { magnitude }\end{array}$ & Station \\
\hline 1 & $\begin{array}{c}\text { Cape Mendocino } \\
1992 / 04 / 25\end{array}$ & 7.1 & 89324 Rio Dell Overpass - FF(CDMG) \\
\hline 2 & $\begin{array}{c}\text { Cape Mendocino } \\
1992 / 04 / 25\end{array}$ & 7.1 & 89486 Fortuna - Fortuna Blvd(CDMG) \\
\hline 3 & $\begin{array}{c}\text { Duzce, Turkey } \\
1999 / 11 / 12 \\
\end{array}$ & 7.1 & 1058 Lamont \\
\hline 4 & $\begin{array}{c}\text { Duzce, Turkey } \\
1999 / 11 / 12 \\
\end{array}$ & 7.1 & 362 Lamont 362(LAMONT) \\
\hline 5 & $\begin{array}{c}\text { Duzce, Turkey } \\
1999 / 11 / 12 \\
\end{array}$ & 7.1 & 531 Lamont 531(LAMONT) \\
\hline 6 & $\begin{array}{c}\text { Duzce, Turkey } \\
1999 / 11 / 12 \\
\end{array}$ & 7.1 & 1060 Lamont \\
\hline 7 & Tabas, Iran 1978/09/16 & 7.4 & 70 Boshrooyeh \\
\hline 8 & Landers $1992 / 06 / 28$ & 7.3 & 12149 Desert Hot Springs(CDMG) \\
\hline 9 & Loma Prieta 1989/10/18 & 6.9 & 57217 Coyote Lake Dam(CDMG) \\
\hline 10 & Northridge 1994/01/17 & 6.7 & 127 Lake Hughes \#9(USGS) \\
\hline 11 & Northridge 1994/01/17 & 6.7 & 90017 LA - Wonderland Ave(USC) \\
\hline 12 & $\begin{array}{c}\text { Chi-Chi, Taiwan } \\
1999 / 09 / 20 \\
\end{array}$ & 7.6 & WGK(CWB) \\
\hline 13 & $\begin{array}{c}\text { Kocaeli, Turkey } \\
1999 / 08 / 17 \\
\end{array}$ & 7.4 & Arcelik(KOERI) \\
\hline 14 & $\begin{array}{c}\text { Imperial Valley } \\
1940 / 05 / 19\end{array}$ & 7.0 & 117 El Centro Array \#9(USGS) \\
\hline 15 & Tianjin & 6.9 & Station NO. 02001 Tianjin Hospital \\
\hline
\end{tabular}




\subsection{Multi-Record IDA Study}

Vertical ground motion records and horizontal ground motion records in the EW direction of the selected ground motions were used as input for the IDA study. Such a study, correspondingly produces sets of IDA curves, can be plotted on the same graph. (Figure 14(a) and Figure 14(b)). By the IM-based rule, the capacity point can be obtained. As we are able to summarize a suite of records by having, for example, mean, $16 \%, 84 \%$ fractiles, which are practically coincident with the mean, mean-sigma and mean+sigma values. These values can accurately characterize the distribution of the seismic demand and capacity of the structure for frequent or rare earthquakes. According to the capacity point, the critical displacements under the vertical ground motion records $\left(\mathrm{Y}_{\max }\right)$ and horizontal ground motion records $\left(\mathrm{X}_{\max }\right)$ are acquired respectively. The critical vertical displacements of the $16 \%, 50 \%$ and $84 \%$ fractiles are $0.32 \mathrm{~m}, 0.37 \mathrm{~m}, 0.44 \mathrm{~m}$, respectively, which corresponds to $1 / 235,1 / 200,1 / 170$ of the structure span. The critical horizontal displacements of the $16 \%, 50 \%$ and $84 \%$ fractiles are $0.15 \mathrm{~m}, 0.17 \mathrm{~m}, 0.19 \mathrm{~m}$, respectively, which corresponds to $2.2 \%$, $2.5 \%, 2.8 \%$ of the column height.

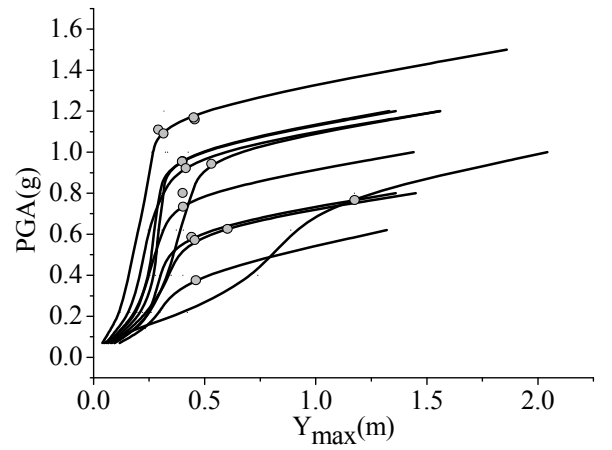

(a) Vertical Ground Motion Records

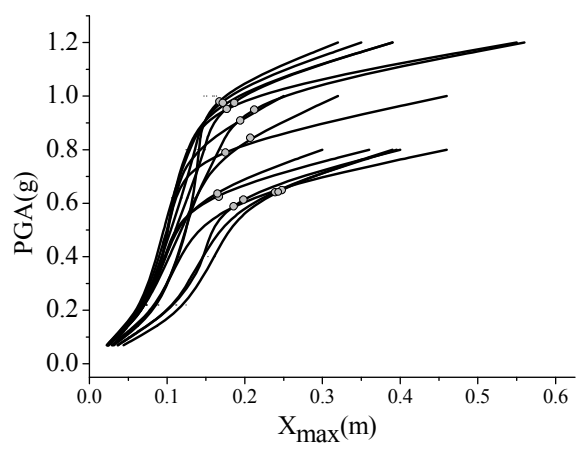

(b) Horizontal Ground Motion Records

Figure 14. Critical Displacement vs. PGA

\section{CONCLUSIONS}

This paper focuses on the earthquake-resistant capability of un-landing steel arch. A shaking table test of an un-landing solid-web steel arch was carried out to present the seismic behavior. By the IM-based rule, the capacity point is acquired of the test model from the IDA curve. Finally, the earthquake-resistant capability of an un-landing latticed steel tubular arch from a real project is evaluated. The major findings from this study are listed below.

1) During the shaking table test, as the acceleration amplitude of the ground motion input increases, the internal damage in the model is cumulative after the earthquake. The acceleration response at the arch-top is largest.

2) The maximum displacement response and the maximum stress at the quarter point of the arch are larger than other test points. All these results reflect that the added braces could effectively help decreasing the displacement and deformation of the un-landing steel arch. The seismic response under the Tianjin wave is the largest while that under the Loma Prieta wave is the least, since the predominant frequency of the Tianjin wave is closest to the fundamental frequency of the model.

3) IDA approach is applied in the un-landing steel arch. A single IDA curve is plotted, which fits the test result. By the IM-based rule, the capacity point of the structure is acquired. 
4) The earthquake-resistant capability of the un-landing latticed steel tubular arch is evaluated by the multi-record IDA study from a real project. Summarizing a suite of records by having mean, $16 \%, 84 \%$ fractiles, the critical vertical displacements of the $16 \%, 50 \%$ and $84 \%$ fractiles are $0.32 \mathrm{~m}, 0.37 \mathrm{~m}, 0.44 \mathrm{~m}$, respectively, which corresponds to $1 / 235,1 / 200,1 / 170$ of the structure span. The critical horizontal displacements of the $16 \%, 50 \%$ and $84 \%$ fractiles are $0.15 \mathrm{~m}, 0.17 \mathrm{~m}, 0.19 \mathrm{~m}$, respectively, which corresponds to $2.2 \%, 2.5 \%, 2.8 \%$ of the column height.

\section{ACKNOWLEDGEMENTS}

This research project is supported by the National Natural Science Foundation of China (No. 51078259 and No. 51308386) and Research Fund for the Doctoral Program of Higher Education of China (No.20130032110044). Support from the funding agency above is gratefully acknowledged.

\section{REFERENCES}

[1] Tanami, T. and Hangai, Y., "Dynamic Experiments and Earthquake Observation of Reticulated Single-layer Domes", International Symposium on Practical Aspects in the Computation of Shell and Spatial Structures, Belgium, 1987, pp.221-230.

[2] Tanami, T. and Hangai, Y., "Shaking Table Tests for the Dynamic Behaviors of Reticulated Single-layer Dome by Use of a Spring Model", International Colloqium on Space Structures for Sports Buildings, China, 1987, pp.101-111.

[3] Li, G.Q., Shen, Z.Y., Ding, X. and et al, "Shaking Table Experimental Study on R2 Steel Roof Model of Shanghai Pudong International Airport Terminal Subjected to Three Dimensional Earthquakes”, Journal of Building Structure, 1999, Vol.34, No.14, pp.18-27.

[4] Fan, F. and Shen, S.Z., "Study on the Shaking Table Experiment and the Vibration Reducing Experiment of Single Layer Reticulated Shells", Journal of Harbin University Civil Engineering Architecture, 2000, Vol.33, No.3, pp.18-22.

[5] Xing, J.H., Liu, X.D., Fan, F. and et al, "Shaking Table Experiment Research on Seismic Behavior of Single-layer Latticed Cylindrical Shell", Journal of Building Structure, 2004, Vol.25, No.6, pp.1-8.

[6] Liu, J.S., Qiu, T. and He, M.W., "Shaking Table Experiment Study on Performance of Long-span Steel Transfer Trusses”, World Earthquake Engineering, 2006, Vol.22, No.4, pp.145-149.

[7] Vamvatsikos, D., "Seismic Performance, Capacity and Reliability of Structures as seen through Incremental Dynamic Analysis", Stanford University, Stanford, CA, 2002.

[8] Vamvatsikos, D. and Fragiadakis, M., "Incremental Dynamic Analysis for Estimating Seismic Performance Sensitivity and Uncertainty", Earthquake Engineering and Structural Dynamics, 2010, Vol.34, No.13, pp.141-163.

[9] Vamvatsikos, D. and Cornell, C.A., "Applied Incremental Dynamic Analysis”, Earthquake Spectra, 2004, Vol.20, No.2, pp.523-553.

[10] Vamvatsikos, D. and Cornell, C.A., "Developing Efficient Scalar and Vector Intensity Measures for IDA Capacity Estimation by Incorporating Elastic Spectral Shape Information", Earthquake Engineering and Structural Dynamics, 2005, Vol.34, No.13, pp.1573-1600.

[11] Vamvatsikos, D. and Cornell, C.A., "Direct Estimation of the Seismic Demand and Capacity of Oscillators with Multi-linear Static Pushovers through IDA”, Earthquake Engineering and Structural Dynamics, 2006, Vol.35, No.9, pp.1097-1117.

[12] Vamvatsikos, D. and Cornell, C.A., "Incremental Dynamic Analysis", Earthquake Engineering and Structural Dynamics, 2002, Vol.31, No.3, pp.491-514. 
[13] Yang, D.B., Zhang, Y.G. and Wu, J.Z., "Application of Incremental Dynamic Analysis in the Collapse Evaluation of Single-layer Latticed Dome", Spatial Structure, 2010, Vol.16, No.3, pp. 91-96.

[14] Pi, Y.L. and Trahair, N.S., "In-plane Buckling and Design of Steel Arches", Journal of Structure Engineering, ASCE, 1999, Vol.125, No.110, pp.1291-1298.

[15] Pi, Y.L. and Bradford, M.A., "In-plane Strength and Design of Fixed Steel I-section Arches", Engineering Structure, 2004, Vol.26, No3, pp.291-301.

[16] Sakimoto, T. and Komatsu, S., "Ultimate Strength Formula for Steel Arches", Journal of Structure Engineering, ASCE, 1983, 109, pp.613-27.

[17] Pi, Y.L. and Trahair, N.S. "Out-of-plane Inelastic Buckling and Strength of Steel Arches", Journal of Structure Engineering, ASCE, 1998, Vol.124, No.2, pp.174-83.

[18] Spoorenberg, R.C., Snijder, H.H. and Hoenderkamp C.D. "A Theoretical Method for Calculating the Collapse Load of Steel Circular Arches”, Engineering Structure, 2012, Vol.38, No.2, pp.89-103.

[19] Lu, Y., "Theoretical Analyses and Experimental Research on Collapse Mechanism of Large-span Arched Frame", Tianjin University, Tianjin, China, 2012.

[20] "Load Code for the Design of Building Structures" (GB50009-2001, 2006 edition), China, 2006.

[21] Wang, L., "Seismic Response Analyses of Long-span Rigid-frame Bridge and the Shaking Table Model Test", Beijing Jiaotong University, Beijing, China, 2010.

[22] Huang, H.H., "Design and Application Technology of the Shaking Table Test", Beijing, China, Seismological Press, 2008.

[23] Li, Z.X., "Theory and Technology of Structure Test", Tianjin, China, Tianjin University Press, 2006.

[24] FEMA, "Recommended Seismic Design Criteria for New Steel Moment-frame Buildings" Report No. FEMA-350, SAC Joint Venture, Federal Emergency Management Agency, Washington, DC, 2000. 